\title{
GÉNERO Y MEDIACIÓN: LA FIGURA MASCULINA EN TELEVISIÓN
}

GENDER AND MEDIATION: THE MALE FIGURE ON TELEVISION

Luis Alfredo Arias Hernández 121J17083@egresados.ujat.mx

Carlos Arturo Olarte Ramos olarte4@hotmail.com 
Para citar este artículo:

Arias-Hernández, Luis y Olarte-Ramos, Carlos. (2019). Género y mediación: la figura

masculina en televisión. Espacio I+D, Innovación más Desarrollo. VIII(21) 45-62. doi:

http://dx.doi.org/10.31644/IMASD.21.2019.a03

\section{RESUMEN}

Los medios masivos de comunicación constituyen industrias culturales de alto consumo entre la población mexicana, convirtiéndose en un referente para explicar la cultura popular. De ellos, la televisión se mantiene como un medio de influencia popular, a partir de mensajes que busca responder a las necesidades de información y entretenimiento de todos los sectores. En materia de género y representación cultural, los mensajes televisivos asocian la figura masculina con el estereotipo del hombre fuerte, exitoso y productivo, con el que se invisibiliza una realidad masculina mexicana, trasgrede el desarrollo humano y refuerza la inequidad en las relaciones entre varones y mujeres. Tal situación implica un conflicto silencioso que violenta a los Derechos Humanos. Por ello es necesario regular el medio y el mensaje para transformar las estructuras tradicionales de poder en sistemas democráticos, a partir de la mediación cognitiva como método alterno de solución de controversias.

\section{Palabras clave}

Conflicto; masculinidad; televisión; mediación cognitiva. 
The mass media are cultural industries of high consumption amongst Mexican population, becoming a reference to explain the popular culture and the social behavior. From them, television keeps going a high popular influence mass, from messages that seek to respond to the information and entertainment needs of all sectors. In matter of gender and cultural representation, the TV messages associate the masculine figure with the stereotype of the strong, successful and productive man, which invisibilizes a reality of the masculinities in Mexico, transgress the human development and reinforces the inequity between man and women. This situation implies in a silent conflict that violence the Human Rights and the legal environment of the television as a media. That is why is necessary to rule the media and the message in order to transform the traditional structures of power in the democratic systems, taking the cognitive mediation as an alternative method of solution of controversies.

\section{Keywords}

Conflict; masculinity; television; cognitive mediation. 
L a masculinidad y la feminidad son conceptos que adquieren significado a partir de las conexiones entre sí, como delimitación social y oposición cultural. En el caso de la masculinidad, su conceptualización tradicional está vinculada con el poder, por lo que ser hombre significa tener y ejercer poder, con características como ganar, ordenar, lograr objetivos y ser duro, incluso, dominar a las mujeres y a otros varones.

La demostración masculina de poder significa controlar sentimientos, emociones y necesidades afectivas, para evitar la pérdida de dominio y el control sobre los otros, y el temor de que le atribuyan características femeninas, que son absolutamente rechazadas (Hardy y Jiménez, 2001).

Connell (2003) define masculinidad como una construcción social e histórica, cambiante de una cultura a otra, en distintos momentos históricos, a lo largo del curso de la vida de cada individuo y entre diferentes grupos de hombres de acuerdo con su clase social, raza o etnia; se basa en valores físicos que posteriormente se transforman en valores morales, y que la familia, escuela, medios de comunicación y sociedad en general enseñan explícita e implícitamente la forma en que el sujeto debe pensar, sentir y actuar como hombre (Hardy y Jiménez, 2001).

La construcción que Seidler (2000), Cruz (2006) y Montesinos (2005) hacen de la masculinidad, está asociada con la restricción corporal y afectiva; Corneau (1991) afirma que estas prohibiciones son formas demostrativas de la masculinidad entre los varones. Los medios de comunicación masifican esta construcción social a partir de mensajes donde se presenta al varón vinculado con el poder y apartado de la afectividad, promoviendo la reproducción de comportamientos que se enmarcan en las prescripciones sociales de género, al respecto, apunta Metz "Los medios de comunicación, especialmente la televisión, juegan un papel trascendental en la construcción de la identidad social; y su extraordinaria difusión, los convierten en agentes por excelencia para instituir y reafirmar imaginarios que perpetúan las brechas de género" (2016: 2).

En ese contexto, los varones constituyen lo que Orozco (1997) define como audiencia: sujetos culturales capaces de significar su producción material y simbólica, pero también de reproducir sin cuestionar las significaciones ofrecidas en los medios; ello posibilita la influencia entre los receptores, de los modelos hegemónicos con la que son construidas las figuras masculinas transmitidas por los medios de comunicación.

En este artículo se presenta una reflexión sobre la representación de la figura masculina proyectada en televisión abierta mexicana, a partir de la exploración de la perspectiva de género, los Derechos Humanos y la Ley Federal de Radio y Televisión, para sugerir la aplicación de la mediación cognitiva que impulse contenidos televisivos más democráticos sobre las masculinidades. 


\section{MASCULINIDAD COMO CONFLICTO}

Los seres humanos conforman grupos al relacionarse con los demás, y en conjunto integran sociedad. Cada grupo representa una cultura que refleja y garantiza la permanencia de sus creencias, valores y acciones, por lo que la multiplicidad de concepciones de vida posibilita la existencia de conflictos.

En materia de género interesa explorar cómo cada cultura determina el reconocimiento de los seres humanos. Por un lado existe el enfoque esencialista que rige la visión de vida a partir de características diferenciales delimitadas por la biología, la herencia y la evolución (tal sistema reconoce la existencia de hombre y mujer), y por otro, la perspectiva de la polarización que establece dos lados diferentes pero complementarios: lo masculino y lo femenino (Rocha y Díaz, 2011). En la sociedad contemporánea occidental, la representación sociocultural de las personas se establece desde el nacimiento, considerando los genitales de hombre o mujer para asignarles el género masculino o femenino.

El género, tal como lo conceptualizó Lamas (2002, 2013), atribuye características femeninas y masculinas a cada sexo, a partir de las ideas que cada cultura establece sobre la diferenciación sexual; esta construcción simbólica determina actividades y comportamientos para cada individuo. A su vez, Connell (1997) establece que el género configura la práctica social a través del tiempo.

El concepto género se usa como referente para determinar la identidad, es decir, lo que los sujetos deciden para sí cuando tienen conciencia de su existencia, aunque socialmente le sea impuesta desde el nacimiento. En la identidad de género se encuentra el rol de género, que son las tareas que cada sujeto realiza a partir de su construcción social. A todas estas relaciones sobre lo masculino y lo femenino se denomina cultura de género.

La cultura de género se refiere al conjunto de normas, reglas, expectativas y mitos que son transmitidos de múltiples formas y a través de diferentes agentes con el propósito de incorporar a los nuevos individuos a la sociedad asegurando su funcionamiento "óptimo" (Rocha y Díaz, 2011: 19).

El punto de partida de los estudios con perspectiva de género es el reconocimiento de la subordinación social y política de las mujeres en un sistema social dominado por los varones. Para Lagarde (1996), la perspectiva de género tiene como uno de sus fines contribuir a la construcción subjetiva y social de una nueva configuración a partir de la resignificación de la historia, sociedad, cultura y política desde y con las mujeres y varones. 
Desde ese enfoque se busca proporcionar los elementos para analizar lo que acontece a las mujeres y a los hombres de momentos históricos definidos, en sus relaciones genéricas precisas, y además conforma los marcos conceptuales en que se interpretan de manera compleja las sociedades y las culturas: su organización y su imaginería, su ritualización, sus cosmovisiones, sus formas ideológicas y sus formas de dominio, de mansedumbre, de reproducción del orden político genérico, de alejamiento de los cánones, de rebeldía y de construcción de alternativas. Y esto abarca desde las relaciones personales e íntimas, hasta las que se dan consuetudinaria y explícitamente en las estructuras de la sociedad civil y del Estado (Caséz, 1998: 108).

La producción académica sobre género está fundamentada en el debate sobre el poder, identidad y estructuración de la vida social (Tena, 2014; Castañeda, 2008; Olavarría, 2008); estos estudios propician enfoques interdisciplinarios que articulan contribuciones de grandes áreas de conocimiento de las ciencias humanas y sociales, tales como la sociología, análisis histórico, teoría política, antropología, psicología y psicoanálisis (Bonan y Guzmán, 2007).

En el caso de la masculinidad, conceptualizarla implica el riesgo de limitarla a un estereotipo vinculado a la normativa social para ser hombre, excluyendo a los varones que por decisión u obligación no están de acuerdo con el significado tradicional de la masculinidad; esta situación hace necesario el reconocimiento a las múltiples masculinidades, donde se incluyan las identidades transexuales, transgéneros, intersexuales, intergéneros, así como a quienes conforman grupos vulnerables como los indígenas, los de la tercera edad y los adolescentes.

La configuración social de la masculinidad sienta expectativas de comportamiento entre los varones, ya que les exige demostración constante de poder; no hacerlo les provocaría una situación de vulnerabilidad frente a las críticas de quienes responden a las prescripciones sociales de género.

Existen varones que aun cumpliendo con el código de comportamiento correspondiente, no están de acuerdo que se les considere como género dominante porque afirman que hay acciones que no deberían ser exclusivos para la masculinidad, sino ser compartidos por el otro género ${ }^{1}$, o bien, tienen el deseo de involucrarse con tareas consideradas propias de la feminidad ${ }^{2}$.

$1 \quad$ Los varones de generaciones más recientes son educados con mayor perspectiva de género, que los hace ser sensibles a la búsqueda de la equidad. Son sujetos que observan que las mujeres que les rodean han incursionado al campo laboral, y que realizan actividades que anteriormente eran exclusivos de los varones, como las carreras de ingenierías o los oficios relacionados con la construcción y la transportación.

2 El ejemplo más claro es la paternidad, derecho que han fortalecido a partir del involucramiento del varón durante la gestación, el parto y el posparto. Cada vez más se observan varones en el cuidado de los hijos, incluso, realizan actividades domésticas como cooperación para la educación familiar. 
La permanencia y reproducción de esta dualidad entre las generaciones más recientes, ha provocado lo que Bell (1987) llama "paradoja de la masculinidad", que consiste en que como varones son educados para mantener los privilegios sociales atribuidos al género masculino, pero se les inculca la idea de la paridad de género, provocándoles conflicto intrapersonal para decidir qué es lo más adecuado para ellos en relación con las mujeres.

La cultura disidente, conformada por quienes critican la polarización y que pugnan por la diversidad de género, comulga con la idea de que la masculinidad no es exclusiva de los varones, lo mismo que la feminidad respecto a las mujeres. Existen mujeres masculinas y hombres femeninos a partir de sus características de personalidad y roles que desempeñan en los escenarios donde se desarrollan. Esta percepción provoca la existencia de otro conflicto que es más de construcción social: la ceguera respecto a la construcción de ser masculino y ser femenino.

La familia y la escuela, por mencionar dos instituciones, son núcleos de socialización donde se transmiten las características asignadas para el varón y para la mujer, papel que se refuerza, incluso se desvirtúa, con el contenido de los medios masivos de comunicación.

En un análisis semántico sobre la figura masculina presentada en medios impresos, específicamente en publicidad de revistas, se visualiza el varón como un sujeto superior, con símbolos de poder que le respaldan el estatus social adquirido por el hecho de ser hombre (Olarte y otros, 2015). Para Connell (1997) son hombres dominantes, machos alfa que sobresalen en un mundo masculino, en donde los que no cumplen con el estereotipo del hombre físicamente atractivo, fuerte y exitoso, se aleja de la esfera privilegiada para convertirse en hombres subordinados y marginados, vinculados en muchos de los casos con expresiones de la feminidad.

Se aprecia que al ser hombres tienen en el espacio público un escenario para mostrarse como tal: están al acecho de las mujeres para conquistarlas, cumpliendo con ello la exigencia de ser los que deben cortejar en una relación interpersonal amorosa (Olarte y otros, 2015).

Pese a que cumplen con estereotipos del hombre occidental, en donde se privilegia la delgadez, la piel blanca, la altura y lo físico, se rompe con la creencia del hombre que, por ser hombre, se aleja de lo estético y lo saludable; son mostrados como sujetos que se preocupan por su cuerpo y aspecto físico, por su salud y bienestar, por ello los modelos proyectados son adultos jóvenes, con figura torneada a partir del ejercicio, que implica el cuidado de la salud.

Sin embargo, el hecho de cuidar la salud, y en ocasiones mostrar ciertas emociones, no significa que evidencien modelos emergentes de la masculinidad, porque el sólo cuidado de la apariencia, más que ser saludable, connota poder, y con ello, la reproducción de la hegemonía (Olarte y otros, 2015). 
Otro conflicto es la ridiculización mediática al que son sometidos los varones que no cumplen con las expectativas establecidas, ya que en muchos de los casos los muestran como sujetos afeminados, connotando como negativo al género femenino. En esa configuración se perciben hombres muy femeninos, o bien travestidos, vinculados a orientación y/o preferencia distinta a la heterosexualidad ${ }^{3}$, que dan pauta a pensar que un varón con tal identidad siempre será como mujer.

Se deja a un lado aquellas figuras de varones con características masculinas que cumplen con roles establecidos desde su nacimiento por las prescripciones sociales de género, y que respetan en parte la normativa social de comportamiento, pero que han decidido para sí una orientación, preferencia y/o identidad sexual distinta a la heteronormatividad, y no por ello restan valor a su existencia como ser humano, como persona y como varón; sin embargo, cuando los demás saben de tal identidad, en su mayoría son blanco de burlas que reflejan un machismo exacerbado.

\section{III- ESTEREOTIPOS EN TELEVISIÓN}

De los medios masivos de comunicación tradicionales, la televisión es el canal de mayor impacto social, pese al dominio radiofónico en zonas semiurbanas y rurales, debido a que su alcance se registra en áreas urbanas ${ }^{4}$.

De acuerdo a la Encuesta Nacional sobre el Uso del Tiempo (ENUT) 2014, los habitantes en México de 12 años y más utilizan algún medio masivo de comunicación, por un promedio de 13 horas semanales (INEGI, 2015).

El Anuario Media Performance 2011 menciona que el grado de penetración de la televisión en los hogares es muy alto, ya que 98.8\% tiene acceso a este medio, además de que $32.2 \%$ cuenta con televisión de paga; asimismo hay al menos una televisión encendida por más de ocho horas por día, y de lunes a viernes $78.5 \%$ de los consumidores sintonizan canales de televisión abierta, que desciende a $72.9 \%$ los fines de semana. Resulta significativo que $44 \%$ de las personas que cuentan con televisión cerrada dedican más tiempo a mirar canales abiertos (Іворе AGм México, 2011).

La televisión mexicana tiene en sistema abierto dos cadenas nacionales que dominan la programación a través de sus diversos canales, mientras que en el sistema cerrado aumenta la cantidad de televisoras pero comparten el

3 La heterosexualidad es la orientación y/o preferencia que caracteriza a la sociedad heteronormativa, como un deber ser para hombres y mujeres; por ello desconoce a las identidades divergentes.

4 La población en México durante 2010 era de 112 millones 336 mil 530 habitantes, de los cuales el $77.8 \%$ se ubicaba en zonas urbanas, y el $22.2 \%$ en zonas rurales (INEGI, 2011). 
cuadrante con producción extranjera. Es Las Estrellas el canal que concentra más de una quinta parte de la audiencia nacional, 15\% lo acapara el Canal 5, $13 \%$ el Canal 13, seguida por Canal 7 con $9.3 \%$ y Canal 9 con $7.3 \%$. El resto se reparte, en fracciones minúsculas, en los demás canales de televisión abierta y entre los canales de paga (IBOPE AGM México, 2011).

Pese a que existe diversidad de programas para todo tipo de público, en la televisión abierta mexicana predominan las telenovelas y las series como formas de entretenimiento poblacional.

El Anuario Media Performance 2011 indicaba que entre los quince primeros lugares de preferencia en programación, diez fueron ocupados por telenovelas; en segundo orden de preferencias están los eventos deportivos y los noticieros.

Las telenovelas más exitosas alcanzan entre 15 y $20 \%$ del rating total, es decir la proporción de la audiencia que está viendo un determinado programa, comparado con el total de la audiencia potencial, que a su vez refiere al total de los hogares con televisión, estén o no encendidas. Estos programas llegan alcanzar hasta 40\% de rating cuando la población hace uso de la televisión en el momento del conteo (IвоPE AGM México, 2011).

Tales estadísticas demuestran que la televisión en México no responde a un interés educativo sino a fines lucrativos, cuya población consumidora tiene preferencia por las producciones que maquillan o actúan la realidad, con poca importancia por los hechos que verdaderamente dan sentido a la realidad; esto es, las telenovelas y los talk show registran mayor rating que los programa de opinión.

La televisión pudiera coadyuvar el trabajo en pro de la educación en el país, a partir de programas y mensajes que construyan saberes para la vida. Sin embargo, al ser parte de un sistema capitalista, la industria televisiva responde a intereses de las altas esferas que dominan la programación, convirtiendo a este medio en una herramienta de manipulación y ceguera social.

El potencial educativo de la televisión abierta es amplio, así lo han demostrado los países de mayor desarrollo en esta materia. El ejemplo de Europa es sobresaliente pero no son excepción los casos de América Latina (Chile, Brasil, Colombia, Argentina, Uruguay) en que se han buscado y logrado alternativas. La televisión por cable da también evidencia de que con programas con enfoque cultural y educativo se pueden alcanzar cuotas de mercado importantes. Es sobre todo una cuestión de definición de prioridades y de trabajo sustantivo en este ámbito. Pero de que se puede se puede (Rodríguez, 2014).

Como medio de sociabilización, la televisión contribuye a formar identidad, a establecer cultura, "a construir su historia desde los procesos culturales en cuanto articuladores de las prácticas de comunicación con los movimientos sociales" (Martín-Barbero, 1991: 178). 
Las prácticas de varones y mujeres que buscan la equidad e igualdad de género constituyen un movimiento social que ha desencadenado hechos para transformar la realidad de las relaciones humanas. Obliga a revisar la historia de cómo los hombres imponían su presencia en un sistema patriarcal y cómo las mujeres debían estar subordinadas en espacios silenciosos; impulsa a recorrer el camino del feminismo para conocer los logros de las mujeres y reivindicar su papel en la sociedad; invita a reflexionar sobre la necesidad de investigar a los varones desde perspectivas que alejen el estigma de ser la figura victimaria.

Desde el ámbito académico se apuesta al uso de la televisión para fines educativos que impulsen el desarrollo humano y comunitario. Desde una perspectiva de género, el mensaje televisivo debe reflejar la paridad entre hombres y mujeres, de tal forma que como medio de comunicación divulgue ideas democráticas en la relación genérica.

Desafortunadamente la realidad en el medio indica la predominancia del lenguaje sexista y las pautas comportamentales tradicionales para varones y mujeres. Se aprecia cómo los sujetos son transformados en objetos de poder y placer, despertando el pensamiento hedonista de los consumidores. En ese contexto, la construcción social de masculinidad para la televisión está asociada a la protección, proveeduría, valentía, inteligencia, liderazgo, distintivo y rico, que poseen códigos de conductas y maneras de ser que mantienen la masculinidad más clásica (Metz, 2009).

En la televisión mexicana, sobre todo en las telenovelas, las series y los talk show, la figura masculina responde a estereotipos específicos: los buenos y exitosos generalmente son sujetos con personalidad atractiva, muchas veces apuestos físicamente, voz varonil, altos, generalmente de tez blanca o morena clara, con cuerpo torneado por músculos estéticamente desarrollados, que representan el ideal tradicional del hombre contemporáneo en Occidente; mientras que los varones que representan problemáticas o que ocupan espacios menos privilegiados, son proyectados como sujetos menos atractivos, con cuerpo no tan agraciado, y una serie de dificultades para las relaciones humanas.

También se refleja la tradicional figura del hombre fuerte, machista, heterosexual, homofóbico, conquistador y soez; así como el hombre afeminado, ridiculizado con acciones que hacen pensar que todo varón con características femeninas es homosexual, y a su vez, que todo varón homosexual se comporta como mujer.

Queda claro que la televisión reproduce estereotipos, valoraciones que son permeados por la población ante su pasividad de recepción; esto significa que las masculinidades rurales, las de la tercera edad, las indígenas, las disidentes, por mencionar algunas, tienen poca o nula cabida en la industria televisiva, y si las hay, son poco valoradas. 
Tal aseveración representa un conflicto más en cuestiones de género, debido a que este medio refuerza la inequidad entre varones y mujeres, vinculando el ser masculino con expresiones de fuerza física, cuando en realidad, es un constructo social que posibilita un abanico de formas para el comportamiento y la experiencia de ser masculino.

Al proyectar figuras que no corresponden a la realidad de la mayoría de los varones que habitan este país, existe la posibilidad de que los mensajes televisivos provoquen conflicto de tipo cognitivo, es decir, de contenido del pensamiento, entre quienes hacen y consumen tales mensajes.

Además se identifica que cuando se limita la figura masculina al abuso del poder, se violentan los artículos 5 y 63 de la Ley Federal de Radio y Televisión ${ }^{5}$. El $5^{0}$ hace referencia a la función social de la televisión para mejorar las formas de convivencia humana, entre otros, a través del respeto de la moral, la dignidad humana y los vínculos familiares; además de la evitación de influencias nocivas o perturbadoras al desarrollo armónico de la niñez y la juventud. El $63^{\circ}$ prohíbe todas las transmisiones que causen la corrupción del lenguaje y las contrarias a las buenas costumbres, ya sea mediante expresiones maliciosas, palabras o imágenes procaces, frases y escenas de doble sentido, apología de la violencia o del crimen.

$\mathrm{Al}$ analizar el comportamiento de la figura masculina proyectada por la televisión, se aprecia la transgresión a la moral (cuando el personaje varón casado se vincula afectiva y sexualmente con más de dos mujeres fuera de la institución familiar) y a la dignidad humana (cuando se presenta a un hombre que es sometido a complicadas pruebas para demostrar su hombría); además, el lenguaje obsceno y la violencia en contra de los demás, altera el uso del lenguaje y rompe con lo que se consideran las buenas costumbres.

La tergiversación que la televisión hace de la figura masculina contribuye a establecer un escenario de conflicto. Tal vez estudiar a los varones desde una perspectiva histórica, biológica y cultural haya tenido mayor retribución y apoyo que el estudiar a las mujeres, pero es una realidad que en las investigaciones sobre ellas se presenta a ellos como victimarios.

Sin debatir ese papel que por tradición e imposición ${ }^{6}$ tiene el varón, es necesario aclarar que no se debe limitar la configuración del varón como un sujeto masculino, ni mucho menos afirmar que existe una sola mascu-

5 La Ley Federal de Radio y Televisión fue decretada en 1960 durante el sexenio de Adolfo López Mateos; su reforma más reciente fue en 2012.

6 Por tradición porque desde la antigüedad se ha considerado al varón como sinónimo de poder, y por imposición porque la sociedad asigna a ellos la facultad de mandar; esto es como expresar que los varones son violentamente destinados a ser violentos. 
linidad. El ser humano varón tiene el derecho de disfrutar abiertamente su existencia a como le guste, siempre y cuando no provoque malestar a quienes le rodean; las mujeres tienen el mismo derecho de disfrutar abiertamente su existencia como tal.

Las decisiones de ser implica entonces la existencia de masculinidades y feminidades, que deberían ser reflejados abiertamente por los medios de comunicación, y evitar esas limitaciones de construcción social respecto a los varones y las mujeres con estereotipos que sólo transgreden la pluralidad y la libertad.

El que se proyecte una masculinidad y no las masculinidades, y el que se distorsione la vivencia de los varones que se identifican como masculinos y/o como femeninos, violenta los Derechos Humanos porque finalmente hombre y mujer, masculino y femenino, son seres humanos con capacidad de decisión.

También se agrede el derecho a la igualdad porque el lenguaje televisivo simboliza la inequidad y la discriminación existente, no sólo entre hombres y mujeres, sino entre hombres y entre mujeres; entre adolescentes, adultos y adultos mayores; entre sujetos de zona rural y zona urbana, entre profesiones, entre oficios, entre actividades diversas.

Se limita el derecho a la libertad, tanto personal como sexual porque la existencia de prejuicios provoca la crítica social hacia la decisión particular de ser persona; y se transgreden los derechos colectivos al violentar la paz y la libertad a ser diferente. La sola proyección de la figura masculina que reproduce patrones de conducta asociadas al machismo contribuye a estas violaciones.

\section{MEDIACIÓN DEL MEDIO Y DEL MENSAJE}

El medio de comunicación responde a intereses de minorías porque está a la orden de las esferas de poder. Los consumidores son vistos como entes pasivos fáciles de manipular, que no pondrán obstáculo alguno para absorber mensajes intencionalmente seleccionados como mercancía.

En ese contexto, la transmisión de la figura masculina conceptualizada en una sociedad patriarcal impulsará la reproducción de la hegemonía entre los sujetos, que para la perspectiva de género representa un conflicto. Si tal situación no se reconoce como tal se mantendrán las prácticas sociales de intolerancia y discriminación.

Para evitar lo anterior, se requiere que el conflicto sea reconocido por las partes involucradas, que representaría un primer paso hacia la búsqueda de acuerdos que aminoren y/o desaparezcan los efectos negativos de la disputa.

Esa posibilidad de cambio requiere la participación responsable de quienes elaboran y consumen el mensaje, y buscar el medio más adecuado para unir esfuerzos tendientes a la mejora de las relaciones de género.

Si tal planteamiento se aprecia desde la justicia alternativa, la justicia social equivaldría al mensaje televisivo que responda a la cotidianidad de 
hombres y mujeres del país, y los canales más factibles para llegar al acuerdo, los métodos alternos de solución de conflictos.

Cornelio (2014) define a los medios alternativos como diversos procedimientos mediante los cuales las personas puedan resolver sus controversias, sin necesidad de una intervención jurisdiccional; tales métodos son: mediación, negociación, conciliación y arbitraje. Las personas que participan en estos sistemas pueden ser físicas o morales, quienes de forma voluntaria buscan el acuerdo sin asistir a los tribunales, que posibilita mayor rapidez para la solución.

En el caso de la figura masculina como conflicto, originada por la industria televisiva, se requiere la participación del medio y del receptor para buscar el equilibrio del mensaje (la figura masculina que responda a todas las posibilidades de ser masculino). La aplicación de los métodos alternos de solución de conflictos, específicamente de la mediación, representa una alternativa para la intervención.

Para González (2010) la mediación se define como el procedimiento estructurado en el que dos o más partes en conflicto intentan voluntariamente alcanzar un acuerdo sobre la resolución de sus diferencias con el apoyo y/o ayuda de un mediador. Aladro (2004) considera que la mediación por sí misma es comunicación, y cuando se produce comunicación, dos posiciones que estaban desconectadas quedan unidas, a través de una simbiosis entre un mensaje y un modo de transmitirlo, que ha creado el cauce adecuado para hacerlo.

Las mediaciones son lugares de los que provienen las constricciones que delimitan y configuran la materialidad social y la expresividad cultura de la televisión (...) Cargada tanto por los procesos de trasnacionalización como por la emergencia de sujetos sociales e identidades culturales nuevas, la comunicación se está convirtiendo en un espacio estratégico desde el que pensar los bloqueos y las contradicciones que dinamizan estas sociedades encrucijada, a medio camino entre un subdesarrollo acelerado y una modernización compulsiva (Martín-Barbero, 1991: 203).

Ello significa que los distintos espacios donde se desarrollan varones y mujeres otorgan sentido a la comunicación, que como proceso de intecambio que involucra el contexto social, construye códigos de comportamiento.

Los mismos medios y sus características intrínsecas, determinaciones políticas y económicas, sus lógicas de producción y transmisión, sus lealtades y estilos, son una mediación. Así como lo son las mismas audiencias, siempre situadas, tanto como miembros de una cultura y de varias comunidades de interpretación, como en tanto individuos con un desarrollo específico, repertorios, esquemas mentales y guiones para su actuación social (Orozco, 1997). 
En la mediación se requiere la participación de los involucrados en el conflicto y la figura de un mediador, quien es un sujeto imparcial que funciona como canal para el mensaje que las partes emitan respecto a la disputa, a fin de alcanzar voluntariamente una solución total o parcial al mismo.

De los tipos de mediación se retoma la mediación cognitiva porque es la que persigue transformar las estructuras cognitivas de los sujetos. Martín (1985) considera que la mediación cognitiva provee a los miembros de la sociedad de relatos en los que se les propone una interpretación del entorno (material, social, ideal) y de lo que en él acontece. Tales narraciones ponen en relación los sucesos que ocurren con los fines y las creencias en cuya preservación están interesados determinados grupos sociales.

En este artículo la construcción social de la masculinidad que se transmite en televisión está considerada como un conflicto, por lo que es necesaria la mediación cognitiva de los medios de comunicación a fin de transformar el medio y el mensaje. La sugerencia es que la televisión reconstruya el fondo de la figura masculina para posibilitar el cambio cognitivo de los receptores respecto a lo que se transmite, sobre todo con referencia de que la televisión es un canal de impacto entre la población.

Se busca generar nuevos significados. En este sentido, deja de ser un vínculo pasivo en la transmisión de alguna información constante entre entrada (emisor) y salida (receptor). Tal es en esencia la función de un diálogo como dispositivo de pensamiento. La función dialógica tiende al dinamismo, la heterogeneidad y el conflicto entre voces. En vez de tratar de recibir significados que residen en los enunciados de los hablantes como algo previsto por la metáfora del conducto, el foco está puesto en cómo puede un interlocutor usar textos como si fueran dispositivos de pensamiento y responder a ellos de forma tal que generen nuevos significados (Cesca, 2014: 3).

Estos nuevos significados en el mensaje televisivo dependerán en mucho de la disposición de quienes hacen el medio, para apegarse a la realidad sin alterarla.

La mediación de los medios de comunicación es propuesta como una teoría que involucra el estudio de la producción, transmisión y utilización de la cultura, desde el análisis de los modelos culturales y de sus funciones; y de la utilización de esta mediación como un procedimiento de dominación o control social influyendo sobre la conciencia de las personas (Cuchillo, 2009).

Resulta tal vez utópico que el medio comunicativo en un sistema económico capitalista como la que predomina en Occidente, transforme su contenido para responder más a intereses sociales que particulares, pero si se logra la sensibilización del impacto que los mensajes relacionados con el género tiene en la sociedad, seguramente habrá mayor conciencia de 
la necesidad de participación conjunta de diversos actores para tener una sociedad más democrática.

\section{CONCLUSIONES}

La mediación del medio y del mensaje respecto a la figura masculina televisada representa una oportunidad para transformar la concepción de la masculinidad en México. Para ello se requiere la participación voluntaria de actores sociales que estén dispuestos a construir una sociedad plural, no sólo de nombre sino de acción, que responda a las demandas de reconocimiento de las diferencias.

La reflexión desde la perspectiva de género que sobre la figura masculina se ha hecho, permite identificar la necesidad de contar con una industria cultural más comprometida con la población, que contribuya a la igualdad de género y al fomento de sanas relaciones humanas.

Se requiere también la reflexión exhaustiva del constructo masculinidad que lleve a una reconstrucción del mismo, a fin de socializar que esta categoría social no es exclusiva de los varones, además de que el ser humano varón tiene el derecho de vivir su naturaleza como varón a su libre decisión aun cuando tal vivencia sea contraria a lo socialmente establecido para los varones, sin que ello implique desvalorizarlo como tal.

El cambio de pensamiento respecto a la experiencia de la masculinidad es un proceso posible pero largo y complejo; depende de todos, no sólo de los varones porque hombres y mujeres configuran la realidad social. En esa dinámica se hace necesaria la participación de los medios de comunicación; tal como lo afirma Cuchillo (2009), la tarea de los medios de comunicación consiste en establecer los marcos de referencia adecuados para que los agentes sociales se sitúen en el cambio.

Hacer que la televisión como medio de comunicación esté al servicio social, no como forma de manipulación de las élites, sino como canales de acercamiento entre las diferencias, permitirá que se abra camino para la mediación del medio y del mensaje. 


\section{FUENTES DE INFORMACIÓN}

Aladro, E. (2004). Comunicación y retroalimentación, Madrid: Fragua.

Bella, D. (1987). Ser varón. La paradoja de la masculinidad, Barcelona: Tusquets Editores.

Bonan, C. y Guzmán. V. (2007). Aportes de la teoría de género a la comprensión de las dinámicas sociales y los temas específicos de asociatividad y participación, identidad y poder. Santiago, Chile: Centro de Estudios de la Mujer-CEM.

Caséz, D. (1998). Metodología de género en los estudios de hombres. Revista de estudios de género. La ventana, (8), 100-120.

Castañeda, M. (2008). Metodología de la investigación feminista. Guatemala: Fundación Guatemala, CEIICH UNAM.

Cesca, P. (2014). La mediación cognitiva, un estilo de aprendizaje para enseñar a pensar. Disponible en: http://www.delasallesuperior.edu.ar/biblioteca/ mediacion_cognitiva_noveduc.pdf

Connell, R. (1997). La organización social de la masculinidad. En Valdés, Teresa y Olavarría, José (editores), Masculinidad/es: poder y crisis (pp. 31-48). Chile, Isis Internacional.

Connell, R. (2003). Masculinidades. México: PUEG-UnAM.

Cornelio, E. (2014). Los mecanismos alternativos de solución de controversias como derecho humano, Barataria, 17, 81-95.

Corneau, G. (1991). Hijos del silencio ¿Qué significan hoy la masculinidad y la paternidad? (Alfonso Andrade Franco, Trad.). Barcelona: Circe ediciones. (Trabajo original publicado en 1989).

Cruz, S. (2006). Cuerpo, masculinidad y jóvenes. Iberóforum. Revista de Ciencias Sociales de la Universidad Iberoamericana, 1(1), 1-9.

Cuchillo, V. (2009). La mediación de los medios de comunicación. Disponible en: http://comunicaziones.blogspot.mx/2009/o8/la-mediacion-de-losmedios-de.html

Fernández, A. (2003). Proveedores, machos y cornudos: la masculinidad hegemónica. En Miano, Marinella (comp.), Caminos inciertos de las masculinidades (299-314). México: INAH.

Galtung, J. (1980). ¡Hay alternativas! 4 caminos hacia la paz y la seguridad. Madrid: Tecnos.

González, N. (2010). Apuntes sobre la mediación como medio alternativo de solución de conflictos: el contexto español y mexicano. En All, Paula y otros (editores), Derecho internacional privado -derecho de la libertad y el respeto mutuo- Ensayos a la memoria de Tatiana B. de Moekelt (615-646). Asunción: CEDEP y ASADIP.

Hardy, E. y Jiménez, A. (2001). Masculinidad y género. Revista Cubana Salud Pública, 27(2), 77-88. 
Instituto Brasileño de Opinión Pública y Estadística / AGM México. (IBOPE AGm México). (2011). Anuario Media Performance 2011. Disponible en: https://www.nielsenibope.com.mx/uploads/anuario2011.pdf

Instituto Nacional de Estadística y Geografía. (INEGI). (2011). Panorama sociodemográfico de México. Disponible en: http://www.inegi.org.mx/ prod_serv/contenidos/espanol/bvinegi/productos/censos/poblacion/2010/panora_socio/Cpv2010_Panorama.pdf

Instituto Nacional de Estadística y Geografía. (INEGI). (2015). Encuesta Nacional sobre el Uso del Tiempo (ENUT) 2014. Disponible en: http:// www.inegi.org.mx/saladeprensa/boletines/2015/especiales/especiales2015_07_2.pdf

Lamas, M. (2002). Cuerpo: diferencia sexual y género. México: Taurus.

Lamas, M. (2013). El género, la construcción cultural de la diferencia sexual. México: Porrúa.

Lagarde, M. (1996). Identidad de géneros y derechos humanos. La construcción de las humanas. En: Guzmán, L. y Pacheco, G. (Compiladores). Estudios básicos de derechos humanos. Tomo II. San José: IDH. Comisión de la Unión Europea.

Ley Federal de Radio y Televisión. (2015). Disponible en: http://normatecainterna.sep.gob.mx/work/models/normateca/Resource/222/3/ images/ley_federal_radio_television.pdf

Márquez, M. y De Villa, J. (2013). Medios alternos de solución de conflictos. México: UNAM.

Martín, M. (1985). Mediación cognitiva y estructural. En Moragas, Miquel (editor), Sociología de la comunicación de masas (pp. 141-162). Barcelona: Gustavo Gili.

Martín-Barbero, J. (1991). De los medios a las mediaciones. Comunicación, cultura y hegemonía. México: Gustavo Gill.

Metz, O. (2016). Construcción de estereotipos masculinos y femeninos en la televisión dominicana: diferencias en la percepción de roles. Razón y Palabra, 20(93), 300-319.

Montesinos, R. (2005). Reconstruyendo la masculinidad, el costo de ser varón o construir una nueva masculinidad. Ponencia presentada en Medellín, Colombia.

Olarte, C. y otros. (2015). La figura masculina en la publicidad impresa: un acercamiento desde la comunicación y el género. Ponencia presentada en el Encuentro Nacional AMIC 2015, realizado el 4 y 5 de junio, Querétaro, Qro.

Olavarría, J. (2008). Apuntes para la construcción de una agenda pro género que incorpore a los hombres. En: Astelarra, J. (coordinador), Pacto entre géneros y políticas públicas: género y cohesión social (pp. 30-44). España: Instituto de la Mujer-Ministerios de Igualdad de España.

Orozco, G. (1997). Medios, audiencias y mediaciones. Comunicar, (8), 25-30. 
Perceval, J. (1995). Nacionalismos, xenofobia y racismo en la comunicación. Una perspectiva histórica. Barcelona: Paidós.

Rodríguez, R. (2014). Televisión, televisoras y crisis educativa en México. México: Instituto de Investigaciones Económicas-UnAM. Disponible en: http://www.ses.unam.mx/publicaciones/articulos.php?proceso=visuali za\&idart $=1911$

Rocha, T. y Díaz, R. (2011). Identidades de género, más allá de cuerpos y mitos. México: Trillas.

Seidler, V. (2000). La sinrazón masculina y teoría social. México: UNAM.

Suárez, M. (1996). Mediación: conducción de disputas, comunicación y técnicas. Madrid: Paidós Ibérica.

Tena, O. (2014). Incorporación del trabajo con hombres en la agenda feminista. En: Rocha, T. y Lozano, I. (Compiladores). Debates y reflexiones en torno a las masculinidades: analizando los caminos hacia la igualdad de género (pp. 21-40). México: UnAM. 